07

\title{
Влияние напряжения на эмиссию ионов, инициированных ударной волной из гетерогенного материала (гранита)
}

\author{
(С) И.П. Щербаков, В.И. Веттегрень , Р.И. Мамалимов, Х.Ф. Махмудов \\ Физико-технический институт им. А.Ф. Иофрфе РАН, \\ Санкт-Петербург, Россия \\ ฯ E-mail: Victor.Vettegren@mail.ioffe.ru \\ (Поступила в Редакцию 12 июля 2016 г.)
}

\begin{abstract}
Электрический пробой воздуха около поверхности сжатой пластины из гранита вызывает появление в нем ударной волны. Добежав до обратной стороны пластинки, ударная волна обусловливает последовательное (с интервалом $\sim 50 \mathrm{~ns}$ ) выделение струй плазмы, состоящей из положительно заряженных ионов. Распределение струй по интенсивности экспоненциальное. Пока сжимающее напряжение $P$ не превысит $\sim 0.9-0.95$ от разрушающего $-P_{f}$, его величина не влияет на число и эффективность источников излучения. При $P \approx(0.9-0.95) P_{f}$ ударная волна вызывает появление трещины, разрушающей образец. Одновременно число и эффективность источников ионов возрастают в 3-4 раза. Это явление объясняется увеличением концентрации скоплений дислокаций при ползучести образца.
\end{abstract}

Работа выполнена при финансовой поддержке РФФИ (грант № 160500138).

DOI: $10.21883 /$ FTT.2017.03.44169.292

\section{1. Введение}

До последнего времени о механизме разрушения судили по результатам исследования изменения скоростной зависимости профиля поверхности при образовании трещин [1-4]. Прямые исследования разрушения хрупких тел непосредственно во время действия ударной волны были начаты в [5-9]. В этих работах с использованием метода регистрации фрактолюминесценции (FL) с временны́ разрешением $10 \mathrm{~ns}$ было изучено разрушение образцов из кварца и гранита под влиянием электрического разряда около их поверхности. Было обнаружено, что ударная волна вызывает выделение струй плазмы, состоящих из положительно заряженных ионов и атомов, входящих в состав структурной формулы кварца и гранита. Этот результат показал, что механизмы разрушения под действием ударной волны и механического нагружения различны. Если при механическом разрушении тело разрушается путем образования и роста трещин, то в поле ударной волны - за счет разложения на ионы. Скорость роста трещин в граните составляет $\sim 1 \mathrm{~km} / \mathrm{s}$, а скорость ударной волны в наших условиях нагружения $\sim 5 \mathrm{~km} / \mathrm{s}$ [7]. Эта пятикратная разница в скоростях роста трещин и ударной волны является основной причиной различия механизмов разрушения [5-13].

Настоящая работа продолжает цикл этих исследований. В ней предполагалось выяснить, как влияет величина сжимающего напряжения на процесс выделения ионов под действием ударной волны.

\section{2. Объект и метод исследования}

Блок-схема установки описана в [7-9]. Для исследований был выбран образец гранита с содержанием кварца $\sim 30$ vol.\% и полевого шпата $\sim 70$ vol.\%. Он представлял собой параллелепипед с размерами ребер $L=20 \times 20 \times 40 \mathrm{~mm}$, внутри которого располагалось отверстие для медных электродов, присоединенных к конденсатору. При разряде конденсатора между электродами возникала дуга. Она вызывала появление ударной волны в воздухе и вслед за ней ударной волны в образце. Энергия разряда составляла $\sim 0.2 J$, а мощность $2 \cdot 10^{5} \mathrm{~W}$. Важно, что такая энергия разряда не вызывала разрушение образца.

Разряд приводил к колебаниям образца гранита, которые регистрировались с использованием датчика из пьезокерамики CTS-19 (размер датчика $4 \times 4 \times 1 \mathrm{~mm}$ ). Для исследования временно́й зависимости FL перед образцом устанавливался один из концов кварцевого световода, второй конец которого располагался перед поверхностью фотокатода фотоэлектронного умножителя PMT-136. Напряжения на пьезокерамике и выходе РМТ подавались на вход аналого-цифрового преобразователя ADS-3112 и через каждые 2 ns записывались в память компьютера для дальнейшего анализа и обработки.

Для сжатия образцов использовался пресс PGPR. Разрушающее напряжение исследованного образца гранита $P_{f} \approx 28 \mathrm{MPa}$.

\section{3. Механизм разрушения гранита под действием ударной волны}

При электрическом разряде в промежутке между двумя медными проводниками образуется плазма, состоящая из микрочастиц, атомов и ионов $\mathrm{Cu}[10]$. Она вызывает появление в граните ударной волны сжатия, которая добегает до поверхности образца и приводит к появлению FL. Ее спектр состоит из нескольких 


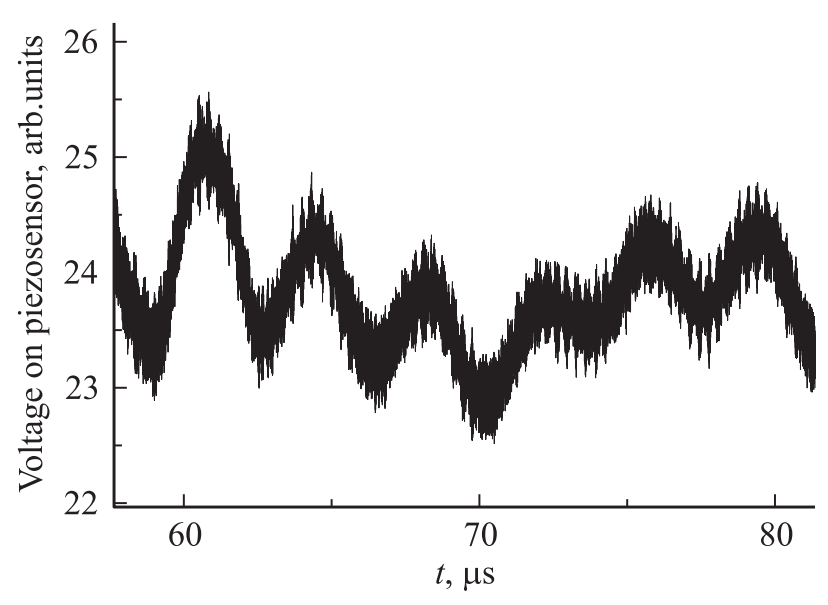

Рис. 1. Собственные колебания образца гранита.

десятков наложенных друг на друга линий, которые соответствуют излучению возбужденных ионов $\mathrm{Si}, \mathrm{O}$, $\mathrm{Ca}, \mathrm{Al}, \mathrm{Fe}, \mathrm{N}$ и $\mathrm{Cu}[8,9]$. Таким образом, под влиянием ударной волны часть гранита разлагается на заряженные ионы.

В работах [11-14] был предложен механизм разрушения, не связанный со скоростью роста трещин. Авторы показали, что при сильных искажениях кристаллической решетки в скоплениях и пересечениях дислокаций возможно пересечение уровней основного и возбужденного электронных состояний. Это может приводить к неадиабатическим переходам между электронными уровнями и распаду межатомных связей с образованием положительно заряженных ионов. Этот механизм не включает в себя явление зарождения микротрещин путем последовательного разрыва связей $\mathrm{Si}-\mathrm{O}$ под влиянием термических флуктуаций. Разрушение происходит атермическим путем и не зависит от температуры и скорости нагружения.

В [15] был предложен механизм, согласно которому струи ионов могут вылетать из-за кумуляции ионов в поpax, расположенных в поверхностном слое гранита. Этот механизм не противоречит описанному выше, так как около пор всегда наблюдается повышенная плотность дислокаций.

Остановимся на деформации образца в поле ударной волны. Как уже отмечалось, разряд вызывал появление ударной волны сжатия, которая многократно отражалась от границ образца, что приводило к собственным колебаниям образца (рис. 1) с полупериодом $\tau \approx L / S$, где $L$ - размер образца $(20 \mathrm{~mm}), S$ - скорость ударной волны в граните. Поскольку $L=20 \mathrm{~mm}$, а $S$ для гранита $\sim 5 \mathrm{~km} / \mathrm{s}[8], \tau \approx 0.4 \mu \mathrm{s}$, что совпадает с измеренным значением полупериода ударной волны $(3.9 \mu \mathrm{s})$.

\section{4. Распределение струй ионов по интенсивности}

Добежав до границы образца, ударная волна сжатия вызывала серию отдельных струй ионов (рис. 2). Число таких струй за время наблюдения достигало $10^{5}-10^{6}$, а время их выделения достигало $~ 300 \mu \mathrm{s}$.

На рис. 3, $a$ в полулогарифмических координатах приведены распределения числа $N$ струй ионов по интенсивности $I$ в отсутствие давления. Они описываются выражением $\ln I=\ln I_{m}-b N$ или $I=I_{m} \exp \left(-N / N_{e}\right)$.

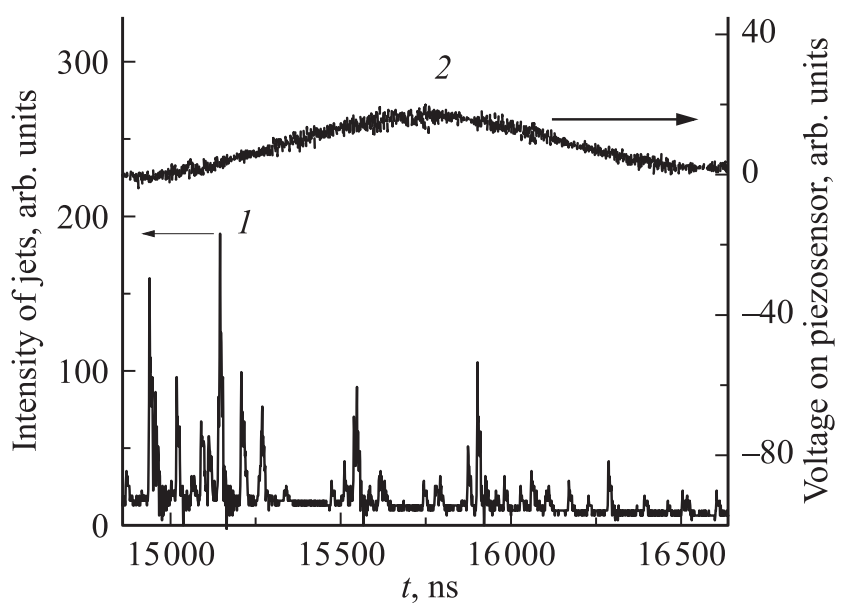

Рис. 2. Струи ионов (1), возникающие при отражении ударной волны (2) от поверхности образца.
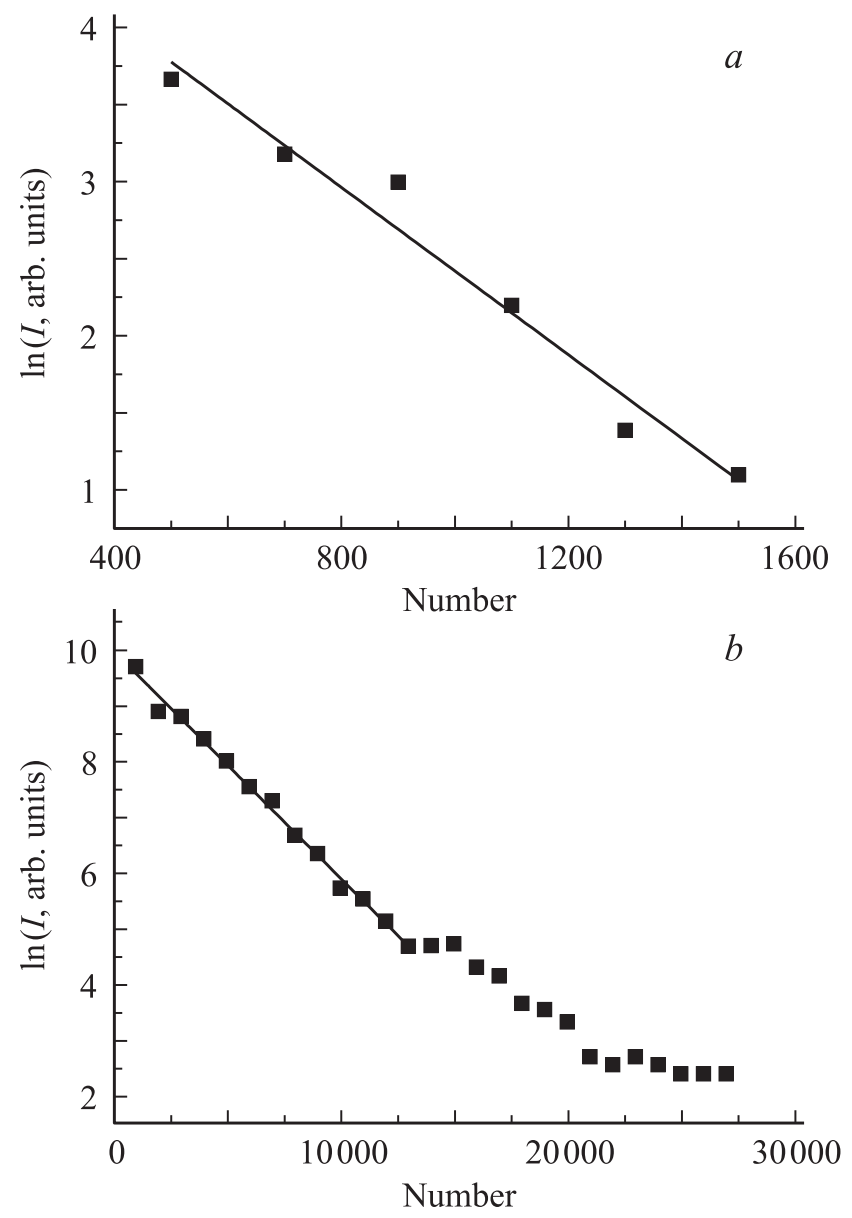

Рис. 3. Распределение интенсивности струй ионов при различных давлениях. $P / P_{f}=0(a), 0.95(b)$. 
Здесь $I_{m}-$ максимальная интенсивность струи, а $N_{e}-$ эффективность источника $(d I / I d N)$. Оказалось, что таким выражением описывается распределение струй, если сжимающее давление не превышает $(0.9-0.95) P_{f}$. По-видимому, такие давления не приводят к появлению новых скоплений дислокаций на границах зерен полевого шпата и кварца.

При давлении $(0.9-0.95) P_{f}$ число струй увеличивается на порядок из-за ползучести образца. По-видимому, при ползучести образуются новые скопления дислокаций. В этих условиях экспоненциальное распределение по интенсивности выполняется только для самых мощных струй (рис. $3, b$ ). Оказалось, что для таких струй величина $\ln I_{m}$ растет на $10 \%$ (т.е. число струй, вылетевших из наиболее эффективного источника, растет в 3 раза), а эффективность источников $N_{e}-$ в 4 раза. Это показывает, что чем мощнее источник, тем сильнее влияет на него давление.

\section{5. Заключение}

Ударная волна вызывает появление нескольких сотен струй плазмы, состоящей из положительно заряженных ионов. Если сжимающее давление не превышает $\sim 0.9-0.95$ от разрушающего напряжения, его величина не оказывает заметного влияния на распределение интенсивности излучающих источников. При давлении, близком к разрушающему, интенсивность наиболее мощных источников плазмы резко возрастает.

\section{Список литературы}

[1] В.В. Адушкин, А.А. Спивак. Геомеханика крупномасштабных взрывов. Недра, М. (1993). 319 с.

[2] В.Е. Фортов. УФН 177, 348 (2007).

[3] Г.И. Канель, В.Е. Фортов, С.В. Разоренов. УФН 177, 809 (2007).

[4] H.I.P. Galvez. Miner. Eng. 24, 1638 (2011).

[5] В.И. Веттегрень, В.С. Куксенко, И.П. Щербаков. ЖТФ 81, 4, 148 (2011).

[6] В.И. Веттегрень, В.С. Куксенко, И.П. Щербаков. ФТТ 54, 1342 (2012).

[7] В.И. Веттегрень, А.В. Воронин, В.С. Куксенко, Р.И. Мамалимов, И.П. Щербаков. ФТТ 56, 315 (2014).

[8] В.И. Веттегрень, И.П. Щербаков, В.С. Куксенко, Р.И. Мамалимов. ФТТ 56. 1767 (2014).

[9] В.И. Веттегрень, В.С. Куксенко, И.П. Щербаков. Физика Земли 4, 1 (2016).

[10] К.Б. Абрамова, И.П. Щербаков, А.И. Русаков. ЖТФ 69, 2 , 137 (1999).

[11] В.А. Закревский, В.А. Пахотин. ФТТ 52, 1083 (2010).

[12] V.A. Zakrevskii, A.V. Shuldiner. Phil. Mag. B 71, 2, 127 (1995).

[13] В.А. Закревский, А.В. Шульдинер. ФТТ 41, 900 (1999).

[14] A.V. Shuldiner, V.A. Zakrevskii. Rad. Protection Dosimetry 65, 1-4, 113 (1996).

[15] Е.Л. Зильбербранд, Г.С. Пугачев, А.Б. Синани. Письма в ЖТФ 20, 6, 45 (1994). 